\title{
Caffeine intake reduces sleep duration in adolescents
}

\author{
Francesca Lodato $^{a, b}$, Joana Araújo ${ }^{a, c, d}$, Henrique Barros ${ }^{a, c, d}$, Carla Lopes ${ }^{a, c, d}$, \\ Antonella Agodi ${ }^{b}$, Martina Barchitta ${ }^{b}$, Elisabete Ramos ${ }^{a, c, d, *}$ \\ ${ }^{a}$ Department of Clinical Epidemiology, Predictive Medicine and Public Health, University of Porto Medical School, Porto, Portugal \\ b Department GF Ingrassia, University of Catania, Catania, Italy \\ c Cardiovascular Research \& Development Unity, University of Porto Medical School, Porto, Portugal \\ d Institute of Public Health, University of Porto, Porto, Portugal
}

\section{A R T I C L E I N F O}

Article history:

Received 15 March 2013

Revised 21 June 2013

Accepted 27 June 2013

Keywords:

Adolescent

Caffeine

Sleep duration

Cross-sectional study

Epidemiology

Food

\begin{abstract}
A B S T R A C T
In our study, we hypothesized that higher caffeine intake would be associated with lower sleep duration among 13-year-old adolescents. In addition, we aimed to identify food sources of caffeine intake in this sample. Eligible participants were adolescents who were born in 1990 and attended school in Porto, Portugal, in 2003/2004. Self-administered questionnaires were used, and diet was evaluated using a food frequency questionnaire. From the 2160 eligible participants, only 1522 with valid information regarding their diet were included in this study. In our sample, the median intake of caffeine was $23.1 \mathrm{mg} / \mathrm{d}$, with soft drinks being the major source. Ice tea presented the highest median (25th-75th percentiles) contribution (33.1\% [14.0-52.1]), followed by cola (21.1\% [6.4-37.6]). Regarding cocoa products, chocolate bars presented a median contribution of 5.1\% (1.0-14.0), and snacks containing chocolate had a contribution of 3.0\% (0.5-7.2). Coffee and tea presented a negligible contribution. Adolescents who reported less sleep duration and those who spent more time watching TV during the weekend had a significantly higher caffeine intake. Overall, boys had higher intakes of caffeine from soft drinks, and private school attendees, those who had parents with more education, who reported less television viewing time and had lower body mass index presented higher intakes of caffeine from chocolate. Considering sleeping more than 9.5 hours as a reference class, for each increase of $10 \mathrm{mg} / \mathrm{d}$ in caffeine intake, we found that the odds ratio of sleeping 8.5 hours or less was 1.12 (95\% confidence interval, 1.06-1.19). Our results support the hypothesis that caffeine intake was inversely associated with sleep duration in adolescents.
\end{abstract}

() 2013 Elsevier Inc. All rights reserved.

\section{Introduction}

Caffeine is one of the most commonly consumed psychoactive substances in the world [1] and is available in a variety of dietary sources such as coffee, tea, cocoa, and soft drinks [2]. Today, approximately $80 \%$ of the world's population consumes a caffeinated product every day, with coffee (71\%), soft drinks $(16 \%)$, and tea (12\%) being the most commonly consumed [3].

Caffeine has been widely studied in a variety of areas regarding human health and performance [3]. Many studies confirm caffeine's ability to enhance mood and alertness [4,5], information-processing speed, awareness, attention, reaction

\footnotetext{
Abbreviations: BMI, body mass index; CI, confidence interval; FFQ food frequency questionnaire; OR, odds ratio.

* Corresponding author. Department of Clinical Epidemiology, Predictive Medicine and Public Health, University of Porto Medical School, Alameda Prof Hernâni Monteiro, 4200-319 Porto, Portugal. Tel.: +351 225513 652; fax: +351 225513653.

E-mail address: eliramos@med.up.pt (E. Ramos).
} 
time [6], and exercise performance [7]. However, most of this information has been based on the adult population.

Scientific evidence supports that, when consumed in moderation, caffeine has no adverse health effects [3]. The exact amount of caffeine necessary to produce an adverse effect varies from person to person, depending on their weight and sensitivity to caffeine [8]. Furthermore, caffeine is the most widely used stimulant to counteract the effects of sleepiness, but it also has detrimental effects on subsequent sleep. This is especially evident when sleep is initiated at a time when the biological clock sends a strong waking signal, such as during the daytime [9]. In fact, in the general adult population, sleep problems such as sleep disturbance and daytime sleepiness have been associated with caffeine use [1].

Also at younger ages, caffeine intake may disturb sleep patterns and impair children's daily life activities [10]. Furthermore, an increased risk of caffeine-induced daily headaches was found in children and adolescents [11]. Although more research is needed on the effect that caffeine has among children and adolescents, it is probable that they may present more vulnerability to caffeine effects because in these age groups the caffeine intake is usually less frequent compared with adults [12].

To identify adolescents with higher risk of excessive caffeine intake, we need to study its associated characteristics. In addition, to develop efficient messages aiming to reduce caffeine intake among these groups, identifying the caffeine food sources, beyond those most well known, is essential because updated evidence on food sources of caffeine intake is scarce for adolescents $[2,12,13]$.

In this study, we hypothesized that higher caffeine intake would be associated with lower sleep duration among 13-yearold adolescents. In addition, we aimed to identify food sources of caffeine intake and characteristics associated with its intake.

\section{Methods and materials}

\subsection{Subjects}

As previously described, eligible participants were adolescents who were born in 1990 and enrolled at either a public or a private school in Porto, Portugal, during the 2003/2004 school year [14]. The eligible participants included 2787 adolescents: 2126 (76.3\%) from public schools and 661 (23.7\%) from private schools. Among these adolescents, 44 (1.6\%) failed to be reached and $583(20.9 \%)$ refused to participate (no signed informed consent form was returned). Consent and the necessary information (at least for part of the planned assessment) were provided by 2160 (1651 public and 509 private school students) adolescents, thus resulting in $77.5 \%$ overall participation $(77.7 \%$ from public and $77.0 \%$ from private schools).

For the present study, we analyzed data from 1522 participants, after excluding participants with missing data on the food frequency questionnaire (FFQ) and outliers, as previously described in detail [15]. Overall, and compared to included participants, more male participants were excluded (52.8\% vs $46.5 \%, P=.008)$, more adolescents with parents less educated ( $<12$ years of education: $81.8 \%$ vs $70.9 \%$ ) and more public school attendees (84.3\% vs $73.1 \%, P<.001)$. For body mass index (BMI) categories and sports participation, excluded adolescents were not significantly different from those included in the analysis.

The study was approved by the Ethics Committee of Hospital S. João, and procedures were developed to guarantee data confidentiality and protection. Parents and adolescents received written and oral information explaining the purpose and the design of the study, and written informed consent was obtained from both.

\subsection{Subject questionnaire and data collection}

Two self-administered questionnaires (completed at home and at school) that comprised information on social, demographic, and behavioral characteristics as well as individual and family history of diseases were used. A physical examination was also performed at school, by a team of experienced health professionals.

As previously described [15], diet was evaluated using a FFQ with the prior 12 months as a reference period and completed by the adolescents at home with the help of their parents or legal guardians. Briefly, the FFQ was designed according to Willett and colleagues [16] and was validated for the Portuguese adult population by comparison with four 7day food records (each one in a different season of the year) $[17,18]$. The FFQ was then adapted for adolescents, including foods more frequently eaten by this age group, and thus, the adolescents' version comprised 91 food items or beverage categories and a frequency section with 9 possible responses ranging from never to 6 or more times per day. An open-ended section for foods not listed in the questionnaire but eaten at least once per week was also included.

Food intake data were obtained by multiplying the frequency of consumption of each food item by the nutrient content of a predefined portion size. To estimate nutrient intake from the evaluated food intake, the software Food Processor Plus (version 7.2, 1997; ESHA Research, Salem, OR, USA), based on values from the US Department of Agriculture, was used. Values for typical Portuguese foods were added, based on the Portuguese Tables of Food Composition, typical recipes, and data from previous studies [17].

Food sources of caffeine and the amount of caffeine provided by each food were determined for each person, then each amount was divided by the total intake of caffeine, and the result was the percentage contribution. Foods or food groups evaluated include coffee, tea, cola, ice tea, chocolate milk, dairy desserts, ice cream, cookies, pastries (such as croissants, cakes, etc), chocolate bars (dark, milk, white; also include chocolate powder), snacks containing chocolate, and chocolate spread. The results were presented as medians (25th-75th percentiles) of the calculated contribution.

Parental education levels were measured as the number of successfully completed years of formal schooling, and we used the information from the parent with the higher level of education. Each school was considered public if it was state administered or private if it was not administered by local or national government. Parental education level and the type of school were used as indicators of socioeconomic class. 
Any planned, regular exercise, regardless of intensity, which was not part of an obligatory curricular activity, was considered sports participation.

Adolescents were asked to report the amount of time spent each weekend when doing the following: television viewing, reading, doing homework, and playing computer or video games. Total time spent in sedentary activities was computed by adding the total time spent in all of the above activities. As indicators of sedentary activities, we used the time (in minutes) spent watching television and the total time spent in sedentary activities.

Sleep duration was estimated by the difference between self-reported bedtimes and wake-up times for weekdays. Then participants were divided into 3 categories, assuming the cutoffs closer to the tertiles of sleep duration: at or below the 8.5 hours per night, above 8.5 but at or below 9.5 hours per night, and above 9.5 hours per night.

As part of the physical examination, weight and height were measured following standardized procedures [19]. Adolescents were classified according to the age- and sex-specific BMI reference percentiles developed by the US Centers for Disease Control and Prevention [20]. Those at or above the 95th percentile were considered obese, and those at or above the 85th percentile but below the 95th percentile were considered overweight.

\subsection{Statistical analyses}

Statistical analyses were performed using the Statistical Package for the Social Sciences (SPSS), version 17.0 (Chicago, IL, USA). Normality was checked using the KolmogorovSmirnov test. The $\chi^{2}$ test was used to compare qualitative variables. Caffeine intake and the contribution of each food group were presented as median (25th-75th percentiles) and compared using the Mann-Whitney or Kruskal-Wallis test, as adequate. To evaluate the association between caffeine intake and sleep duration, odds ratio (OR) and respective $95 \%$ confidence intervals ( $95 \%$ CIs) were computed through multinomial logistic regression, with more than $9.5 \mathrm{~h} / \mathrm{d}$ of sleep duration as the reference. Mean daily caffeine intake in milligrams was divided per 10 , to be included in the model, so that the estimated ORs corresponded to an increase of $10 \mathrm{mg}$ in daily caffeine intake. Estimates were adjusted for energy intake, parental education, and weekend television viewing.

\section{Results}

The median (25th-75th percentiles) intake of caffeine among this sample of 13-year-old adolescents was $23.1 \mathrm{mg} / \mathrm{d}$ (11.643.4). The proportional contribution of food groups to caffeine intake is described in Table 1. Coffee and tea showed a very small contribution to caffeine intake. The major sources of caffeine were soft drinks, with ice tea presenting the highest median contribution (33.1\% [14.0-52.1]), followed by cola with a median value of $21.1 \%$ [6.4-37.6]. Among solid foods, chocolate bars presented a median contribution of 5.1\% (1.014.0), and snacks containing chocolate had a median contribution of $3.0 \%(0.5-7.2)$.

Caffeine intake levels (total and by source) were compared according to participants' characteristics (Table 2). A higher caffeine intake was found among adolescents registered at public schools, those with parents reporting a lower educational level, those reporting no sports participation, and those expending more time in sedentary activities (TV and total). Regarding sleep duration, those reporting less sleep duration had a significantly higher caffeine intake: $27.4 \mathrm{mg} / \mathrm{d}$ of caffeine in the group of lower sleep duration and $22.2 \mathrm{mg} / \mathrm{d}$ in the group of higher sleep duration.

Regarding each source of caffeine intake, the contribution of soft drinks was significantly higher among boys than among girls $(35.0 \%$ vs $30.3 \%, P=.006$, for ice tea; $23.7 \%$ vs $17.2 \%, P<.001$, for cola). The contribution of chocolate bars was higher among adolescents enrolled at private, among those whose parents had higher levels of education, who reported lower amounts of television viewing and had lower BMI (Table 2).

Table 1 - Proportional contribution of food groups to caffeine intake in 13-year-old adolescents

\begin{tabular}{lcccc} 
& \multicolumn{3}{c}{ Sources of caffeine } \\
\cline { 2 - 5 } Beverage/Food group & Median & 25th Percentile & 75th Percentile & Maximum value \\
\hline Beverages & 33.1 & 14.0 & 52.1 & 100 \\
$\quad$ Ice tea & 21.1 & 6.4 & 37.6 & 9.0 \\
Cola & 0.0 & 0.0 & 6.4 & 100 \\
Coffee & 0.0 & 0.0 & 0.0 & 100 \\
Tea & 0.0 & 0.0 & 14.0 & 87.2 \\
Chocolate milk & & & 7.2 & 100 \\
Food & 5.1 & 1.0 & 3.3 & 92.0 \\
Chocolate bars & 3.0 & 0.5 & 2.5 & 89.9 \\
Snacks containing chocolate & 1.2 & 0.3 & 1.9 & 76.8 \\
Cookies & 0.9 & 0.3 & 0.4 & 100 \\
Ice cream & 0.8 & 0.3 & 0.2 & 88.2 \\
Pastry & 0.1 & 0.0 & & \\
Dairy desserts & 0.0 & 0.0 & & \\
Chocolate spread & & & & \\
\hline Values represent percentages. & & & & \\
\hline
\end{tabular}


Table 2 - Caffeine intakes from food or beverages by subjects' characteristics

\section{n (\%) Caffeine intake \\ $(\mathrm{mg} / \mathrm{d})$}

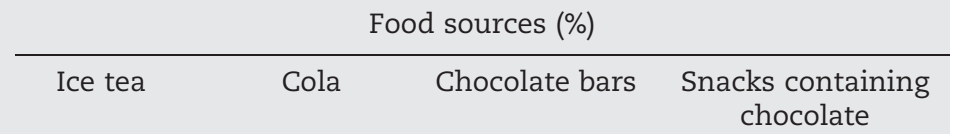

\begin{tabular}{|c|c|c|c|c|c|c|}
\hline \multicolumn{7}{|c|}{ Sleep duration $(\mathrm{h} / \mathrm{d})$} \\
\hline$\leq 8.5$ & $448(29.5)$ & $27.4(13.9-51.6)$ & $35.0(14.9-53.5)$ & $21.6(5.9-39.8)$ & $5.0(1.5-14.4)$ & $2.9(0.9-7.0)$ \\
\hline$>8.5$ and $\leq 9.5$ & $812(53.5)$ & $21.6(10.9-40.0)$ & 31.8 (12.9-51.0) & $21.1(6.7-37.5)$ & $5.3(1.1-13.5)$ & $3.3(0.2-7.2)$ \\
\hline \multirow[t]{2}{*}{$>9.5$} & $259(17.1)$ & $22.2(10.5-42.6)$ & 32.7 (14.4-54.2) & $20.4(5.7-34.5)$ & $4.9(0.0-15.3)$ & $2.7(0.0-6.8)$ \\
\hline & & $P<.001$ & $P=.438$ & $P=.495$ & $P=.402$ & $P=.569$ \\
\hline \multicolumn{7}{|l|}{ Sex } \\
\hline Girls & $815(53.5)$ & $22.3(11.0-43.6)$ & $30.3(11.1-52.2)$ & $17.2(4.2-35.4)$ & $4.9(0.8-14.1)$ & $3.2(0.4-7.2)$ \\
\hline \multirow[t]{2}{*}{ Boys } & 707 (46.5) & $23.6(12.2-43.3)$ & $35.0(18.7-52.0)$ & $23.7(9.8-39.4)$ & $5.3(1.2-14.0)$ & $2.9(0.6-7.1)$ \\
\hline & & $P=.300$ & $P=.006$ & $P<.001$ & $P=.591$ & $P=.501$ \\
\hline \multicolumn{7}{|l|}{ Sports practice } \\
\hline No & 734 (48.9) & $23.9(11.9-46.0)$ & $30.6(12.0-51.5)$ & $21.6(6.0-38.4)$ & $5.1(0.7-14.5)$ & $3.0(0.6-7.4)$ \\
\hline \multirow[t]{2}{*}{ Yes } & 767 (51.1) & $22.2(11.5-41.6)$ & 35.2 (15.4-52.9) & $20.9(6.9-37.1)$ & $5.2(1.2-13.7)$ & $3.1(0.0-7.1)$ \\
\hline & & $P=.043$ & $P=.084$ & $P=.851$ & $P=.546$ & $P=.410$ \\
\hline \multicolumn{7}{|c|}{ TV at weekend (min) } \\
\hline$\leq 120$ & $303(20.7)$ & $18.4(9.9-37.2)$ & $33.8(14.7-50.2)$ & $22.4(6.2-39.0)$ & $7.0(1.6-16.6)$ & $3.5(0.0-7.4)$ \\
\hline $121-240$ & $505(34.4)$ & $22.3(11.3-41.8)$ & 34.1 (14.0-52.7) & $20.8(6.0-36.1)$ & $5.8(1.2-16.0)$ & $3.2(0.4-7.4)$ \\
\hline $241-360$ & $348(23.7)$ & $23.0(11.0-44.9)$ & $33.2(14.2-52.6)$ & $20.5(6.0-36.9)$ & $4.8(1.0-12-6)$ & $3.0(0.5-6.6)$ \\
\hline \multirow[t]{2}{*}{$>360$} & $310(21.1)$ & $28.1(14.7-50.2)$ & $31.2(12.9-52.4)$ & $21.8(8.1-39.7)$ & $4.2(0.0-10.5)$ & $2.6(0.7-7.2)$ \\
\hline & & $P<.001$ & $P=.990$ & $P=.433$ & $P=.002$ & $P=.657$ \\
\hline \multicolumn{7}{|c|}{$\begin{array}{l}\text { Total sedentary activities } \\
\text { at weekend ( } \min )\end{array}$} \\
\hline$\leq 360$ & $356(25.3)$ & $21.9(10.7-42.2)$ & $33.0(12.3-51.6)$ & $21.4(5.7-39.0)$ & $6.1(1.5-15.1)$ & $3.7(0.8-7.8)$ \\
\hline $361-480$ & $303(21.5)$ & $23.0(11.6-44.6)$ & 31.6 (12.9-51.3) & $21.0(4.8-34.9)$ & $6.7(1.3-14.1)$ & $2.9(0.0-7.0)$ \\
\hline $481-600$ & 257 (18.3) & $21.4(10.7-41.8)$ & $31.2(16.6-49.5)$ & $20.2(7.4-37.0)$ & $5.4(1.0-16.0)$ & $2.8(0.0-7.0)$ \\
\hline \multirow[t]{2}{*}{$>600$} & 492 (34.9) & $25.4(13.0-47.0)$ & $35.2(14.6-52.6)$ & $21.7(7.2-39.5)$ & $4.8(0.9-12.5)$ & $2.9(0.7-7.2)$ \\
\hline & & $P=.036$ & $P=.563$ & $P=.551$ & $P=.350$ & $P=.338$ \\
\hline \multicolumn{7}{|l|}{$\mathrm{BMI}^{\mathrm{a}}$} \\
\hline$<85$ th & 1081 (74.1) & $23.5(12.0-43.9)$ & $33.2(14.8-51.4)$ & $21.0(6.4-37.1)$ & $5.5(1.4-15.4)$ & $3.3(0.8-7.4)$ \\
\hline 85th and $<95$ th & $234(16.0)$ & $20.2(9.6-42.2)$ & $36.0(13.5-54.2)$ & $22.8(6.8-40.0)$ & $4.5(0.0-11.1)$ & $2.3(0.0-6.6)$ \\
\hline \multirow[t]{2}{*}{$\geq 95$ th } & $144(9.9)$ & $22.9(11.1-40.2)$ & 30.4 (9.8-51.7) & $20.4(5.7-38.2)$ & $2.8(0.0-9.4)$ & $2.5(0.0-6.3)$ \\
\hline & & $P=.102$ & $P=.436$ & $P=.632$ & $P<.001$ & $P=.008$ \\
\hline \multicolumn{7}{|l|}{ School } \\
\hline Public & 1113 (73.1) & $24.0(12.6-45.8)$ & $32.8(14.2-52.2)$ & $21.1(6.8-37.2)$ & $4.9(0.8-12.5)$ & $3.0(0.6-7.0)$ \\
\hline \multirow[t]{2}{*}{ Private } & 409 (26.9) & $19.5(9.5-39.0)$ & $35.0(12.7-51.8)$ & $21.1(5.5-39.2)$ & $6.6(1.5-16.7)$ & $3.1(0.0-7.4)$ \\
\hline & & $P<.001$ & $P=.833$ & $P=.898$ & $P=.003$ & $P=.701$ \\
\hline \multicolumn{7}{|c|}{ Parental education (yrs.) } \\
\hline $0-6$ & $337(22.3)$ & $28.0(12.9-51.0)$ & $34.2(14.9-53.0)$ & $23.5(6.6-39.4)$ & $3.5(0.0-9.2)$ & $3.1(0.7-7.3)$ \\
\hline $7-9$ & $310(20.6)$ & $25.6(14.2-49.0)$ & $33.8(12.4-52.4)$ & $20.7(7.3-39.1)$ & $4.1(0.0-10.0)$ & $2.4(0.0-6.4)$ \\
\hline $10-12$ & $422(28.0)$ & $22.2(10.7-41.3)$ & $31.7(14.3-52.5)$ & $21.0(6.2-37.1)$ & $5.4(1.5-15.9)$ & $3.5(0.8-7.4)$ \\
\hline \multirow[t]{2}{*}{$>12$} & $439(29.1)$ & $20.2(10.3-37.8)$ & 32.5 (13.3-15.9) & $20.1(5.3-36.5)$ & $7.8(2.0-17.9)$ & $3.3(0.0-7.2)$ \\
\hline & & $P<.001$ & $P=.865$ & $P=.409$ & $P<.001$ & $P=.138$ \\
\hline
\end{tabular}

Values presented are medians (25th-75th percentiles), and statistical differences between medians were determined by Mann-Whitney or Kruskal-Wallis tests.

a According to Centers for Disease Control and Prevention percentiles [21].

The results from the multinomial logistic regression model (Table 3) showed that, after adjusting for energy intake, parental education, and weekend television viewing, an increase of $10 \mathrm{mg}$ in daily caffeine intake was associated with a higher odds of sleeping ( $\leq 8.5 \mathrm{~h} / \mathrm{d}$ (OR, 1.12; 95\% CI, 1.061.19), compared with sleep $>9.5 \mathrm{~h} / \mathrm{d}$.

\section{Discussion}

In our study, the median intake of caffeine was $23.1 \mathrm{mg} / \mathrm{d}$, and its major sources were soft drinks, followed by cocoa products. In addition, we confirmed the hypothesis that higher caffeine intake was associated with lower sleep duration among 13year-old adolescents.

The scientific literature reports a wide range of data regarding caffeine intake in different populations. Among US children younger than 18 years, the mean daily caffeine intake is about $1 \mathrm{mg} / \mathrm{kg}$; in the United Kingdom, the mean intake among children appears to be less than $3 \mathrm{mg} / \mathrm{kg}$. In Denmark, the mean caffeine intake is less than $2.5 \mathrm{mg} / \mathrm{kg}$, and among 10- to 15-year-olds in Australia, the mean caffeine intake is $1.3 \mathrm{mg} / \mathrm{kg}$ [2]. According to the National Health and Nutrition Examination Survey (1999-2002), 12- to 19-year-old adolescents in the United States had a mean (SD) intake of 71.5 (4.3) $\mathrm{mg} / \mathrm{d}$ of caffeine [21], which is 
Table 3 - The relationship between daily caffeine intake and sleep duration in subjects

\begin{tabular}{|c|c|c|c|}
\hline & \multicolumn{3}{|c|}{ Sleep duration $(\mathrm{h} / \mathrm{d})$, OR $(95 \% \mathrm{CI})^{\mathrm{a}}$} \\
\hline & $\leq 8.5$ & $>8.5$ and $\leq 9.5$ & $>9.5$ \\
\hline \multicolumn{4}{|l|}{ Caffeine intake (per 10-mg/d increase) ${ }^{\mathrm{b}}$} \\
\hline Crude & $1.09(1.04-1.14)$ & $1.01(0.96-1.06)$ & Reference \\
\hline Adjusted for energy intake & $1.10(1.04-1.16)$ & $1.00(0.95-1.06)$ & Reference \\
\hline Adjusted for parental education & $1.11(1.06-1.17)$ & $1.03(0.98-1.08)$ & Reference \\
\hline Adjusted for TV at weekend & $1.09(1.04-1.15)$ & $1.02(0.97-1.07)$ & Reference \\
\hline Adjusted for energy intake and parental education & $1.13(1.06-1.19)$ & $1.02(0.97-1.08)$ & Reference \\
\hline Adjusted for energy intake, parental education and TV at weekend & $1.12(1.06-1.19)$ & $1.02(0.97-1.08)$ & Reference \\
\hline
\end{tabular}

similar to that reported for 571 high school students in Croatia (62.8 [59.8] mg/d) [13]. Another study that focused on US adolescents aged 12 to 18 years reported even higher intakes of caffeine (median, $144 \mathrm{mg} / \mathrm{d}$ ) [10]. In our sample, the median intake of caffeine was $22.3 \mathrm{mg} / \mathrm{d}$ in girls and $23.6 \mathrm{mg} / \mathrm{d}$ in boys, corresponding to a median intake of $0.44 \mathrm{mg} / \mathrm{kg}$ in the total sample and suggesting a lower intake compared with other populations.

Data on food contributors to caffeine intake in other populations are scarce. Our results showing soft drinks as the major source of caffeine are in accordance with a study conducted in a cohort of American children aged 6 to 10 years [22]. It is of interest that in our study, ice tea presented a higher contribution to caffeine intake than did cola. This could be related to parents' knowledge regarding soft drinks, and thus, they may allow ice tea consumption because it is seen as a healthier drink than cola.

Our second highest source of caffeine was chocolate products at approximately $8 \%$, which is much lower than the $38 \%$ reported for US adolescents by Ellison et al [22]. However, it is much more in line with data from Croat adolescents that showed about $13 \%$ of caffeine consumption coming from chocolate, which was the third highest source of caffeine [13].

Data from the DAta Food NEtworking study show that household food availability of soft drinks in Portugal is lower compared with other European countries [23]. Although exact data are not available for the same period in all countries, these data indicate a lower availability of the main food source of caffeine in our sample. This may explain the lower intake of caffeine compared with other populations.

Caffeine intake may produce detrimental effects on sleep, resulting in daytime sleepiness. This justifies a careful consideration of risks related to sleep deprivation in combination with caffeine consumption, especially in adolescents. In our results, a higher daily intake of caffeine was reported by those with lower sleep duration ( $\leq 8.5$ hours), although specific contributions from the different food sources were not statistically significant. Although the cross-sectional design of our study does not specifically link lower sleep duration caused by caffeine intake, it is not likely that it happens the other way around because the use of these beverages to reduce daytime sleepiness is usually described for older adolescents [24-26].
Other studies have also reported shorter nocturnal sleep duration [27] or difficulty sleeping [28] among adolescents who had higher caffeine intakes. In a sample of US students, adolescents reporting high caffeine intake were more likely to have difficulty sleeping (OR, 1.9; 95\% CI, 1.62.1) and to be tired in the morning (OR, 1.8; 95\% CI, 1.5-2.1) compared with students reporting a very low caffeine intake [28]. Drescher and colleagues [29] reported an inverse association between caffeine consumption and parentreported total sleep time (regression coefficient, -0.270 ; $95 \%$ CI, -0.463 to -0.077 ) in a cohort of white and Hispanic adolescents. In our study, an increase of $10 \mathrm{mg}$ in caffeine intake, which is approximately the equivalent to a can of ice tea, was associated with lower sleep duration $(\leq 8.5 \mathrm{~h} / \mathrm{d})$ compared with those who slept more than $9.5 \mathrm{~h} / \mathrm{d}$. Our results reinforce the relevance of this intake of caffeine because they highlight the effects in young adolescents, even in those with lower caffeine intakes compared with other populations.

Caffeine intake was higher among adolescents enrolled at public schools and among those whose parents had a lower educational level. Type of school and parental educational level were used as indicators of socioeconomic level, and a previous study conducted in our sample also showed that adolescents of the high socioeconomic class seemed to present a healthier contribution of food groups to nutrient intake [15].

In the present survey, the FFQ we used to assess the caffeine dietary intake levels has some intrinsic limitations. One of these limitations is the use of a predetermined food list that might not be representative of foods eaten by the specific population [30]. Nevertheless, we believe that this potential bias had a very low influence because this FFQ has been previously validated for the adult population $[17,18]$ and was specifically adapted for the adolescents [15]. Another limitation of the FFQ is the reliance on participants' recall and the recruitment of motivated participants, especially in self-administered questionnaires [30]. Our FFQ was selfadministered, but adolescents were given oral instructions, and written instructions were also sent home, along with the questionnaire. Moreover, adolescents completed it with the help of their parents or legal guardians, which may have improved the quality of information. However, the extent to which parents might have an influence on overestimating 
healthy foods (according to what is socially acceptable) and on underestimating unhealthy foods is unknown. In addition, because the FFQ was self-administered, we had to exclude some participants who did not fill in the questionnaire or did not complete it properly. Because those subjects excluded were enrolled more frequently at public schools and their parents presented a lower educational level and because these characteristics were associated with higher caffeine intake, we believe that the caffeine intake in our sample is underestimated.

Regarding sleep duration assessment, an objective measure was not possible to obtain in our study, and sleep duration was estimated through self-reported bedtimes and wake-up times. Although it is not the reference method, a study of high school adolescents found, for weeknights, high correlations between actigraphy and self-reported bedtimes $(r=0.70)$ and wake-up times $(r=0.77)$ [31]. However, we recognize that sleep duration is only a small component of the sleep characteristics, and our data do not allow the study of consequences on other components of the sleep pattern.

On the other hand, we need to mention some strengths of our study. It was conducted in a large population-based sample of adolescents who were recruited at schools, with a high proportion of participation (about 78\%). In addition, because school education is compulsory in Portugal at 13 years of age, schools are an ideal sampling frame for this age range.

We found soft drinks as the major source of caffeine intake, and our results support the hypothesis that caffeine intake could compromise sleep duration in adolescents. However, the intake of coffee and tea was very low, thus suggesting a potential intention to restrict caffeine intake but lack of awareness regarding other important food sources. Appropriate measures of health promotion are needed to ensure that adolescents are given the tools necessary to develop into healthy adults.

\section{Acknowledgment}

This research was supported by the Portuguese Foundation for Science and Technology: POCTI/SAU-ESP/62399/2004, FCOMP-01-0124-FEDER-015750 (Reference FCT PTDC/SAUEPI/115254/2009), and SFRH/BD/78153/2011 (to J.A.).

\section{REFERENCES}

[1] Roehrs T, Roth T. Caffeine: sleep and daytime sleepiness. Sleep Med Rev 2008;12:153-62.

[2] Barone JJ, Roberts HR. Caffeine consumption. Food Chem Toxicol 1996;34:119-29.

[3] Heckman MA, Weil J, Gonzalez de Mejia E. Caffeine (1, 3, 7trimethylxanthine) in foods: a comprehensive review on consumption, functionality, safety, and regulatory matters. J Food Sci 2010;75:R77-87.

[4] Kaplan GB, Greenblatt DJ, Ehrenberg BL, et al. Dosedependent pharmacokinetics and psychomotor effects of caffeine in humans. J Clin Pharmacol 1997;37: 693-703.
[5] Lorist MM, Tops M. Caffeine, fatigue, and cognition. Brain Cogn 2003;53:82-94.

[6] Cysneiros RM, Farkas D, Harmatz JS, von Moltke LL, Greenblatt DJ. Pharmacokinetic and pharmacodynamic interactions between zolpidem and caffeine. Clin Pharmacol Ther 2007;82:54-62.

[7] Doherty M, Smith PM. Effects of caffeine ingestion on exercise testing: a meta-analysis. Int J Sport Nutr Exerc Metab 2004;14: 626-46.

[8] Higdon JV, Frei B. Coffee and health: a review of recent human research. Crit Rev Food Sci Nutr 2006;46:101-23.

[9] Carrier J, Paquet J, Fernandez-Bolanos M, et al. Effects of caffeine on daytime recovery sleep: a double challenge to the sleep-wake cycle in aging. Sleep Med 2009;10: 1016-24.

[10] Calamaro CJ, Mason TB, Ratcliffe SJ. Adolescents living the 24/7 lifestyle: effects of caffeine and technology on sleep duration and daytime functioning. Pediatrics 2009;123: e1005-10.

[11] Hering-Hanit R, Gadoth N. Caffeine-induced headache in children and adolescents. Cephalalgia 2003;23:332-5.

[12] Frary CD, Johnson RK, Wang MQ. Food sources and intakes of caffeine in the diets of persons in the United States. J Am Diet Assoc 2005;105:110-3.

[13] Valek M, Laslavic B, Laslavic Z. Daily caffeine intake among Osijek High School students: questionnaire study. Croat Med J 2004;45:72-5.

[14] Ramos E, Barros H. Family and school determinants of overweight in 13-year-old Portuguese adolescents. Acta Paediatr 2007;96:281-6.

[15] Araujo J, Severo M, Lopes C, Ramos E. Food sources of nutrients among 13-year-old Portuguese adolescents. Public Health Nutr 2011;14:1970-8.

[16] Willett WC, Sampson L, Stampfer MJ, et al. Reproducibility and validity of a semiquantitative food frequency questionnaire. Am J Epidemiol 1985;122:51-65.

[17] Lopes C. Reproducibility and validity of semi-quantitative food frequency questionnaire. Diet and myocardial infarction: a community-based case-control study. Porto: University of Porto; 2000 (in Portuguese).

[18] Lopes C, Aro A, Azevedo A, Ramos E, Barros H. Intake and adipose tissue composition of fatty acids and risk of myocardial infarction in a male Portuguese community sample. J Am Diet Assoc 2007;107:276-86.

[19] World Health Organization. Measuring obesity: classification and description of anthropometric data. Report on a WHO Consultation on the Epidemiology of Obesity. Copenhagen: WHO; 1988 .

[20] Kuczmarski RJ, Ogden CL, Guo SS, et al. 2000 CDC growth charts for the United States: methods and development. Vital Health Stat 2002;11:1-190.

[21] Sugiyama T, Xie D, Graham-Maar RC, Inoue K, Kobayashi Y, Stettler N. Dietary and lifestyle factors associated with blood pressure among U.S. adolescents. J Adolesc Health 2007;40: 166-72.

[22] Ellison RC, Singer MR, Moore LL, Nguyen US, Garrahie EJ, Marmor JK. Current caffeine intake of young children: amount and sources. J Am Diet Assoc 1995;95:802-4.

[23] DAFNE-DAta Food NEtworking. Trends within a country. National and Kapodistrian University of Athens; 2005. Available at: http://www.nut.uoa.gr/dafnesoftweb/Main. aspx?type=trends. Accessed June 2013.

[24] Bryant Ludden A, Wolfson AR. Understanding adolescent caffeine use: connecting use patterns with expectancies, reasons, and sleep. Health Educ Behav 2010;37:330-42.

[25] Shochat T. Impact of lifestyle and technology developments on sleep. Nat Sci Sleep 2012;4:19-31.

[26] James JE, Kristjansson AL, Sigfusdottir ID. Adolescent substance use, sleep, and academic achievement: 
evidence of harm due to caffeine. J Adolesc 2011;34: 665-73.

[27] Pollak CP, Bright D. Caffeine consumption and weekly sleep patterns in US seventh-, eighth-, and ninth-graders. Pediatrics 2003;111:42-6.

[28] Orbeta RL, Overpeck MD, Ramcharran D, Kogan MD, Ledsky R. High caffeine intake in adolescents: associations with difficulty sleeping and feeling tired in the morning. J Adolesc Health 2006;38:451-3.
[29] Drescher AA, Goodwin JL, Silva GE, Quan SF. Caffeine and screen time in adolescence: associations with short sleep and obesity. J Clin Sleep Med 2011;7:337-42.

[30] Willett W. Food-frequency methods. In: Willett W, editor. Nutritional epidemiology. 2nd ed. New York: Oxford University Press; 1998.

[31] Wolfson AR, Carskadon MA, Acebo C, et al. Evidence for the validity of a sleep habits survey for adolescents. Sleep 2003;26:213-6. 